Original Article

\title{
A Study of the Predictive Value of the Modified Tokuhashi Score in Metastatic Spinal Tumour Causing Cord Compression in a Southern Chinese Population 研究改良德橋評分(modified Tokuhashi score)在中國南方人脊柱轉移瘤
造成脊髓壓迫症的預測準確值
}

\author{
Yeung Yuk-Nam ${ }^{\mathrm{a}, *}$, Cheung Ka-Kin ${ }^{\mathrm{a}}$, Lam Tai-Chung ${ }^{\mathrm{b}}$, Cheng Hung-On ${ }^{\mathrm{a}}$, Chow Yuk-Yin ${ }^{\mathrm{a}}$ \\ ${ }^{a}$ Department of Orthopaedics and Traumatology, Tuen Mun Hospital, Tuen Mun, New Territories, Hong Kong \\ ${ }^{\mathrm{b}}$ Department of Oncology, Tuen Mun Hospital, Tuen Mun, New Territories, Hong Kong
}

\section{A R T I C L E I N F O}

\section{Article history:}

Accepted April 2013

\section{Keywords:}

modified Tokuhashi score

Southern Chinese

\begin{abstract}
A B S T R A C T
Introduction: It is generally agreed that operative intervention is beneficial in carefully selected groups of patients with metastatic spinal cord compression (MSCC). Tokuhashi et al have presented a preoperative scoring system to predict patient survival, which is widely used as a guideline for making a decision on whether to operate or not. However, only limited data are available regarding the validity of the Tokuhashi score in Southern Chinese populations.

Materials and methods: We report a series of 128 patients treated in our hospital from 2000 to 2010. All patients were diagnosed to have spinal metastasis of different origins with cord compression. Of the 128 , 59 underwent operation and the remaining 69 received conservative treatments. The Tokuhashi score was then calculated retrospectively. The survival rate was analysed and $p<0.05$ was considered statistically significant.

Results: In our series, the accuracy of the modified Tokuhashi scoring for predicting the survival rate in patients with MSCC was demonstrated to be $79 \%$ (101/128). The poor prognostic group showed statistically significant worse survival than the two better prognostic groups. The type of primary cancer ( $p=0.0015)$, visceral metastasis $(p=0.006)$, and the general condition $(p<0.001)$ were confirmed as significant survival prognostic factors. Nasopharyngeal carcinoma (NPC) had the most favourable outcome with a mean survival of 20.1 months.

Conclusion: The modified Tokuhashi score was statistically correlated to the overall survival of MSCC patients in a Southern Chinese population. The type of primary cancer, visceral metastasis, and the general condition were statistically significant survival factors. We recommend weighting a higher score for NPC in the modified Tokuhashi scoring system in view of its favourable prognosis.
\end{abstract}

\section{中文 摘 要}

目的：脊柱手術對於部份惡性脊柱轉移瘤造成脊髓壓迫症的患者是有成效的。德橋醫生(Tokuhashi)提出了一 個術前評分系統來預測病人的生存率，並於臨床廣泛應用以決定是否進行手術。然而，改良的德橋評 分(modified Tokuhashi score)系統對於中國南方人是否有效，仍然缺乏數據支持。 方法: 由2000至2010年間, 我們對128名於本院治療的患者進行研究。所有患者均診斷為惡性脊柱轉移瘤脊 髓壓迫症。其中59人進行手術冶療，其餘69人則給予保守治療。利用改良的德橋評分作回顧性分析其存活率 並設定 $p$ 值 $<0.05$ 為有統計學有意義。

結果: 79\%的病人能透過改良的德橋評分準確地預測生存期。預後為不良的組別之生存率相對於其他兩個預後 為較好的組別明顯較差。原發腫瘤的類型 $(p=0.0015)$, 內臟轉移 $(p=0.006)$ 和身体狀況 $(p<0.001)$ 被確認為重 要的生存預測因素。鼻咽癌的存活率最佳, 平均生存期為20.1個月。

\footnotetext{
* Corresponding author. E-mail: sraymondy@yahoo.com.
} 


\section{Introduction}

Metastatic spinal cord compression (MSCC) is still a challenging problem for spine surgeons. It is a common complication secondary to spinal metastasis and can present as a neurological emergency. Clinical symptoms range from severe pain to neurological deficit and can adversely affect patients' quality of life. It has been agreed that operative intervention is beneficial in some selected groups of patients who have malignant MSCC. ${ }^{1-3}$ The aims of palliative surgery are to provide symptomatic relief and restore stability as well as function without causing further morbidity. The prognosis and survival of the patients are still the most important considerations for surgery. So far, various scoring systems have been developed to predict the survival of patients to guide the treatment strategy. ${ }^{1-3}$

Tokuhashi et al presented a preoperative scoring system to predict the survival rate in patients with spinal metastasis in $1990 .{ }^{1}$ The scoring consists of six parameters including general condition, number of extraspinal bony metastases, number of vertebral metastases, number of visceral metastases, primary site of cancer, and spinal cord palsy. Tokuhashi et al revised the system for diverse tumours types in 2005 . $^{2}$ This scoring system categorises patients into three prognostic groups. It suggests that operation is beneficial for patients with a predicted survival beyond 6 months. This system had been shown to give a predicted value of up to $84 \%^{2}$ and was widely accepted as the guideline for treatment of spinal metastasis. Others reported predicted values in the range of $60-79 \%{ }^{4-10}$ To our knowledge, only limited studies are available regarding the predictive value of the Tokuhashi scoring system in a Southern Chinese population. The purpose of our study was to evaluate the predictive value and usefulness of the Tokuhashi scoring system in a Southern Chinese population.

\section{Materials and methods}

A total of 144 patients who developed spinal metastases with spinal cord compression were recruited retrospectively from 2001 to 2011 in our hospital.

Of these 144, 73 had spinal operative treatment for cord compression; of these 73 patients, 13 were excluded because of uncertain diagnosis of malignancy, no definite radiological evidence of cord compression, or cord compression due to haematological malignancy. One patient was excluded because of an inadequate follow-up period of less than 12 months.

Data from 71 patients treated conservatively were collected for the study. All the cases were recruited in 2010 in view of completeness of data. Most of them received radiotherapy and steroids. Two patients were excluded because of diagnosis of haematological malignancy.

Finally, 128 patients were retained for analysis; 59 of them had surgical treatment of MSCC while 69 patients received conservative therapy. The patients were followed up for 12 months at least, if alive. The modified Tokuhashi score ${ }^{2}$ was calculated according to the patient's data stated in the preoperative period, and all the parameters were analysed at the time of diagnosis of malignant MSCC. The date of magnetic resonance imaging was considered as the date of diagnosis and death or the date of last study follow-up assessment (July 25, 2012) was considered as the end point.
All patients suspected to have malignant spinal cord compression were staged with a standardised diagnostic work-up by oncologists and orthopaedic surgeons and/or a specialised physician. The diagnosis of malignant MSCC was confirmed with either magnetic resonance imaging and/or contrast computed tomography. Clinical examination, abdominal ultrasound, plain radiographs, computed tomography, and bone scan were used to search for metastasis in other sites. Positron emission tomography was also used to determine the presence of the primary tumour and metastasis in some cases.

Our indication for surgery was a pathological fracture with neurological compression. Excision of spinal metastasis was performed only in highly selected patients with a single spinal metastatic lesion. Decompression and instrumentation were performed to achieve spinal stability and relieve neurological compromise. Chemotherapy, radiotherapy, immunotherapy, hormonal therapy, and/or local irradiation of the spinal metastasis were included as part of the treatment according to the oncologists' recommendations in both operated and conservative treatment groups.

Statistical analysis was carried out using IBM SPSS (International Business Machines Corporation Statistical Package for the Social Sciences, version 20). The Mann-Whitney $U$ test was used for continuous variables, whereas the Chi square test or Fisher exact test was used for categorical variables. Survival data were analysed using Kaplan-Meier survival curves. Comparisons of the survival data of the three prognostic groups proposed by Tokuhashi et al were performed with the log-rank test and Cox proportional hazards model. Various parameters were analysed by the Cox proportional hazards model for univariate and multivariate analyses. All $p$ values were studied by a two-tailed test, and $p<0.05$ was considered statistically significant.

\section{Results}

\section{Demographic data}

There were 91 males and 37 females in this study. The mean age at the time of diagnosis was 60.2 years. Standard deviation (SD) was 12.0, range was 28-90, and median was 59. At the end-point assessment, 123 patients had died and five were alive. The prevalent sites of primary cancer were lung (29.7\%), breast (14.8\%), prostate (9.4\%), liver (7.8\%), and nasopharynx (7.8\%; Figure 1).

The most frequent site of spinal metastasis was the thoracic spine (46.1\%), followed by the lumbosacral (15.7\%) and cervical (7.8\%) regions; $16.4 \%$ patients had metastases involving two regions and $14.1 \%$ patients had metastases in more than two regions (Figure 2).

There was no statistically significant difference between the operative group and the conservative group in age, sex, site of primary carcinoma, and sites of metastatic lesion ( $p=0.096$; Table 1).

The mean survival of all patients was 7.6 months ( $S D=14.3$; range from 5 days to 121.9 months; median $=3.1$ months). An evaluation of the modified Tokuhashi score is shown in Table 2.

\section{Operative group}

There were 38 males and 21 females. The mean age at the time of diagnosis was 58.6 years $(S D=10.9$; range $=28-83$; 


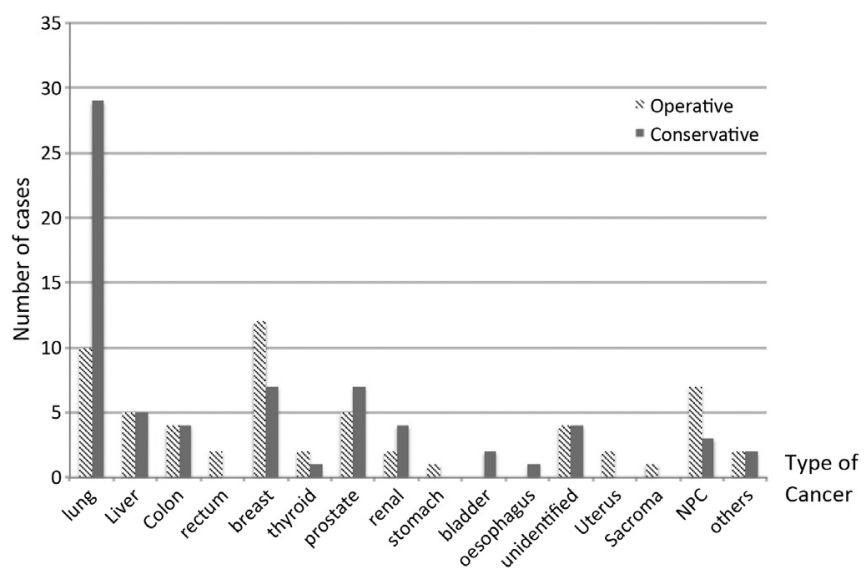

Figure 1. Prevalence of primary cancers of spinal metastasis with cord compression. $\mathrm{NPC}=$ nasopharyngeal carcinoma.

median $=58)$. The mean survival was 12.5 months $(\mathrm{SD}=19.4$; range from 7 days to 121.9 months; median $=5.3$ months). The mean modified Tokuhashi score was $8.6(\mathrm{SD}=2.3$; range $4-14$; median $=8$ ). Among all operative patients, 33 belonged to the poor prognostic group (modified Tokuhashi score 0-8) with a median survival of 3.1 months, 19 belonged to the moderate prognostic group (modified Tokuhashi score 9-11) with a median survival of 9.9 months, and seven belonged to the good prognostic group (modified Tokuhashi score 12-15) with a median survival of 12.2 months (Figure 3 ). The difference in survival of the three prognostic groups was statistically significant $(p=0.030)$.

\section{Conservative group}

There were 53 males and 16 females. The mean age at the time of diagnosis was 61.6 years $(S D=12.9$; range $=35-90$; median $=59$ ). The mean survival was 3.5 months $(\mathrm{SD}=5.0$; range from 5 days to 27.4 months; median $=1.7$ months). The mean modified Tokuhashi score was 5.5 (SD = 2.6; range: $1-13$; median $=5$ ). Among all conservative patients, 59 patients belonged to the poor prognostic group (modified Tokuhashi score $0-8$ ) with

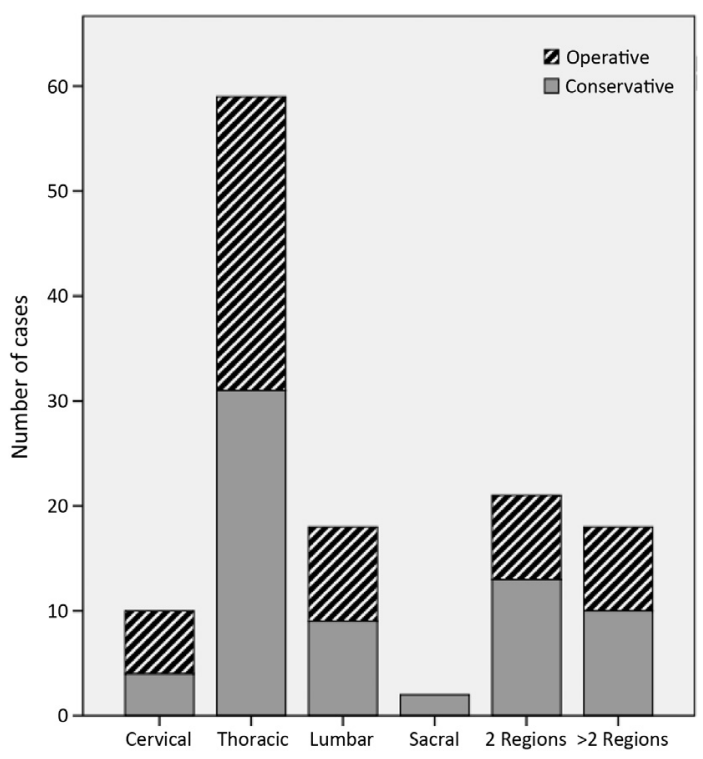

Figure 2. The spinal regions of metastasis.
Table 1

Clinical features of the 128 patients with metastatic spinal cord compression

\begin{tabular}{llllll}
\hline & & Operation & Conservative & Total & $p$ \\
\hline Sex & Male & 38 & 53 & 91 & 0.171 \\
& Female & 21 & 16 & 37 & \\
Age & Mean (SD) & $58.6(10.9)$ & $61.3(12.9)$ & - & 0.155 \\
Sites of spinal & Cervical & 6 & 4 & 10 & 0.669 \\
metastases & Thoracic & 28 & 31 & 59 & \\
& Lumbar & 9 & 9 & 18 & \\
& Sacral & 0 & 2 & 2 & \\
& Two level & 8 & 13 & 21 & \\
& More than & 8 & 10 & 18 & \\
& two levels & & & & \\
\hline
\end{tabular}

$\mathrm{SD}=$ standard deviation.

a median survival of 1.4 months, nine patients belonged to the moderate prognostic group (modified Tokuhashi score 9-11) with a median survival of 2.1 months and one patient belonged to the good prognostic group (modified Tokuhashi score 12-15) with a median survival of 20.0 months. The difference in survival rate among the three prognostic groups was statistically significant $(p=0.029$; Figure 4$)$.

\section{Overall survival}

The mean modified Tokuhashi score was $7.0(\mathrm{SD}=3.0$; range $1-$ 14 ; median $=7$ ). The survival data of the three prognostic groups are shown in Table 3. The difference in survival among the three prognostic groups was statistically significant ( $p<0.001$; Figure 5 ).

The results of univariate and multivariate analyses of the predictors of overall survival are shown in Tables 4 and 5 . In univariate regression analysis, sex, general conditions, status of visceral metastasis, primary type of cancer, and neurological deficit affected survival. In multivariate regression analysis, only the type of primary cancer, visceral metastasis, and the general condition were confirmed as significant survival prognostic factors.

Although the modified Tokuhashi score is a statistically significant prognostic factor of patient's actual survival, we can only demonstrate significant survival difference between the poor $(0-8)$ prognostic subgroup and the other two better prognostic groups. There was no significant survival difference between the moderate (9-11 points) and good (12-15 points) prognostic groups (Table 6).

\section{Discussion}

Although patients with MSCC have relatively limited life expectancy, appropriate treatment can significantly improve their quality of life. Depending on the tumour biology, spinal metastasis may respond favourably to different nonsurgical treatments such as chemotherapy, radiation therapy, and hormonal therapy. However, spine surgery should always be an option especially for patients with profound neurological deficit and spinal instability. Patchell et al have demonstrated that there was greater improvement in ambulatory status after decompressive spine surgery and radiation compared with radiation alone. ${ }^{11}$ Fujibayashi et al have shown that $81 \%$ of patients were either very satisfied or satisfied with palliative surgery with correlation to improvement of neurological status. ${ }^{12}$ However, surgical risks must be weighed against predicted life survival to justify surgical intervention in this group of metastatic patients. Tokuhashi et al and Tomita et al suggested a surgical procedure for patients with predicted survival beyond 6 months.,

Predicted life expectancy is still the main concern before operation. Several preoperative scoring systems have been developed to provide guidance for selection of patients as well as type and magnitude of spinal surgery. ${ }^{1-3,13,14}$ The modified Tokuhashi 
Table 2

Modified Tokuhashi scoring for survival prognosis in spinal metastasis of our patients

\begin{tabular}{|c|c|c|c|c|}
\hline Parameters & Score (points) & $\begin{array}{l}\text { No. of patients in the } \\
\text { operative group }\end{array}$ & $\begin{array}{l}\text { No. of patients in the } \\
\text { conservative group }\end{array}$ & Total no. of patients \\
\hline \multicolumn{5}{|l|}{ General conditions } \\
\hline Poor (KPS10-40) & 0 & 1 & 22 & 23 \\
\hline Moderate (KPS 50-70) & 1 & 47 & 40 & 87 \\
\hline Good (KPS 80-100) & 2 & 11 & 7 & 18 \\
\hline \multicolumn{5}{|l|}{ No. of extraspinal bone metastases foci } \\
\hline$\geq 3$ & 0 & 13 & 35 & 48 \\
\hline $1-2$ & 1 & 8 & 14 & 22 \\
\hline 0 & 2 & 38 & 20 & 58 \\
\hline \multicolumn{5}{|l|}{ No. of metastases in the vertebral bodies } \\
\hline$>3$ & 0 & 36 & 57 & 93 \\
\hline 2 & 1 & 13 & 6 & 19 \\
\hline 1 & 2 & 10 & 6 & 16 \\
\hline \multicolumn{5}{|l|}{ Metastases to the major internal organs } \\
\hline Unremovable & 0 & 8 & 36 & 44 \\
\hline Removable & 1 & 1 & 1 & 2 \\
\hline No metastases & 2 & 50 & 32 & 82 \\
\hline \multicolumn{5}{|l|}{ Primary site of the cancer } \\
\hline $\begin{array}{l}\text { Pancreas, oesophagus, stomach, bladder, } \\
\text { osteosarcoma, lung }\end{array}$ & 0 & 11 & 33 & 44 \\
\hline Liver, gall bladder, unidentified & 1 & 9 & 7 & 16 \\
\hline Others & 2 & 16 & 10 & 26 \\
\hline Uterus, kidney & 3 & 3 & 4 & 7 \\
\hline Rectum & 4 & 1 & 0 & 1 \\
\hline Thyroid, prostate, breast, carcinoid & 5 & 19 & 15 & 34 \\
\hline \multicolumn{5}{|l|}{ Spinal cord palsy (Frankel grading *) } \\
\hline Complete (Frankel A and B) & 0 & 1 & 10 & 11 \\
\hline Incomplete (Frankel C and D) & 1 & 46 & 41 & 87 \\
\hline None (Frankel E) & 2 & 12 & 18 & 30 \\
\hline \multicolumn{5}{|l|}{ Tokuhashi prognostic group } \\
\hline Survival less than 6 mo & $0-8$ & 33 & 59 & 92 \\
\hline Survival more than 6 mo & $9-11$ & 19 & 9 & 28 \\
\hline Survival more than 12 mo & $12-15$ & 7 & 1 & 8 \\
\hline Summary & & 59 & 69 & 128 \\
\hline
\end{tabular}

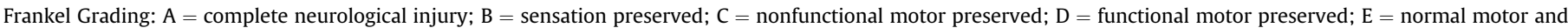
sensory function.

KPS = Karnofsky's performance status.

scoring is one of the most popular systems and is most frequently reviewed for its accuracy. Tokuhashi et al reported the modified scoring system with a reliability of $86.4 \%$ in 118 prospectively evaluated patients and $82.5 \%$ in 246 retrospectively evaluated patients in 2005 . $^{2}$ Ulmar et al had demonstrated a reliability of $71.0 \%$ (154/217) with the modified Tokuhashi scoring system. Ulmar et al

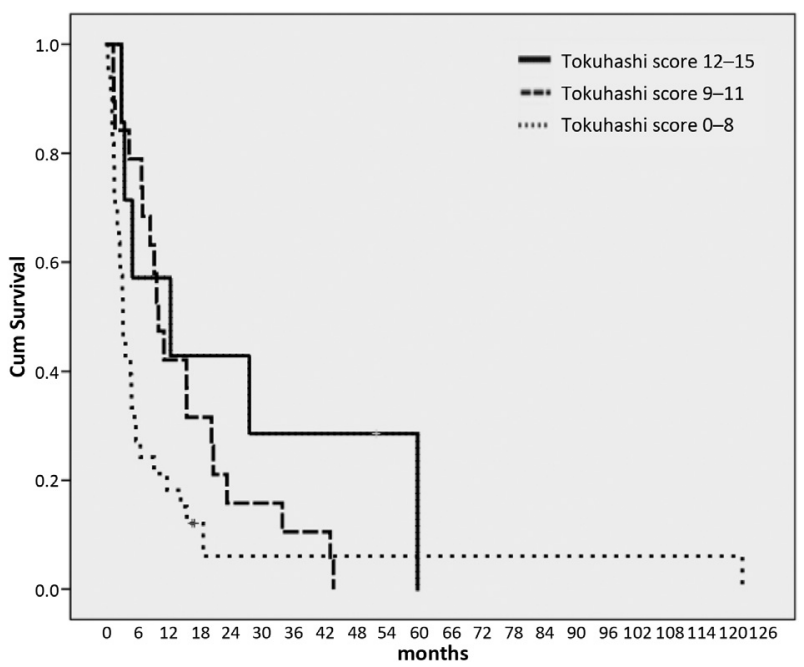

Figure 3. Survival curve for the three prognostic groups in operative patients. Cum $=$ cumulative. further categorised the patients into two groups, namely, survival less than 1 year and survival beyond 1 year, which showed an even higher reliability of the scoring up to $74.2 \%(161 / 217) .{ }^{4}$ In another study, Ulmar et al also demonstrated the use of Tokuhashi score with the modification of the prognosis group and showed statistically significant predicted survival rate in patients with breast cancer. ${ }^{6}$ Yamashita et al reported a reliability of $79 \%(67 / 85)$ with

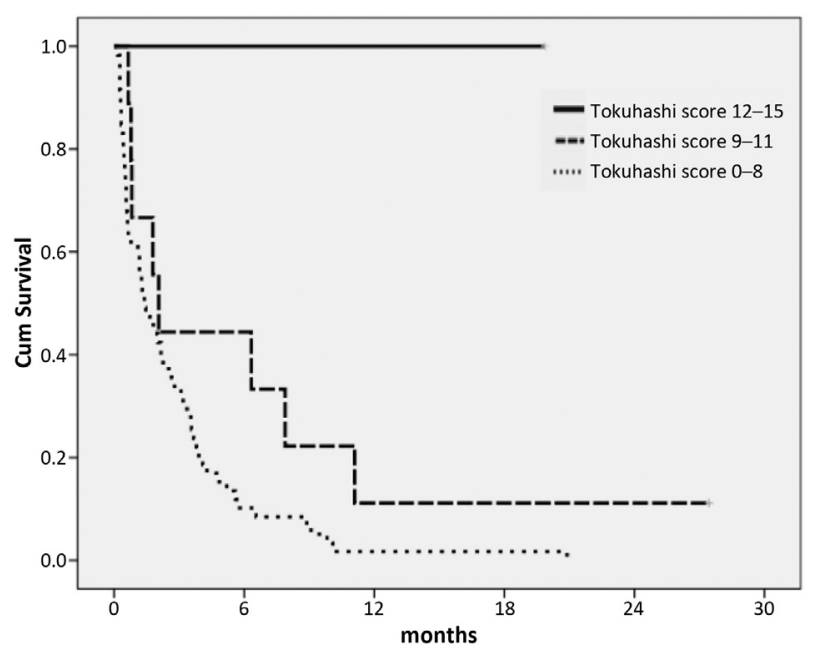

Figure 4. Survival curve for the three prognostic groups in conservative patients. Cum $=$ cumulative. 
Table 3

Accuracy of the modified Tokuhashi scoring

\begin{tabular}{llll}
\hline & $0-8$ points & $9-11$ points & $12-15$ points \\
\hline$N$ & 92 & 28 & 8 \\
Mean \pm SD (mo) & $4.9 \pm 13.1$ & $12.3 \pm 12.3$ & $22.7 \pm 22.1$ \\
Median (mo) & 2.2 & 8.7 & 12 \\
Correctly estimated & 77 & 19 & 5 \\
Incorrectly estimated & 15 & 9 & 3 \\
Accuracy & $83.70 \%$ & $69 \%$ & $63 \%$ \\
\hline
\end{tabular}

$\mathrm{SD}=$ standard deviation.

the modified Tokuhashi score. They also showed that the performance status and existence of organ metastases significantly correlated with poor survival. ${ }^{10}$ Putz et al demonstrated the positive correlation of neurological improvement after surgery to the Tokuhashi score. ${ }^{15}$ Pointillart et al showed an overall accuracy of less than 60\% with the modified Tokuhashi scoring system in a European population. ${ }^{8}$

A total of $79 \%$ (101/128) accuracy of the modified Tokuhashi scoring system in predicting the survival rate among patients with MSCC was demonstrated in our series. The accuracy of the three prognostic subgroups is $84 \%(77 / 92)$ in the poor prognostic group, $69 \%(19 / 28)$ in the moderate prognostic group, and $63 \%(5 / 8)$ in the good prognostic group. The relatively small sample size in the moderate and good prognosis groups can bias the statistical power of this result. This limitation is also present in most of the other studies. $^{4,8-10}$ Our result showed a significant survival difference between the poor prognostic subgroup and the other two better prognostic groups only. This finding was compatible with the result of Wibmer et al and Yamashita et $\mathrm{al}^{7,10}$ in which the Tokuhashi scoring system failed to distinguish significantly between the good and moderate prognostic groups.

We believed that the extent of surgery is highly individualised and cannot just depend on the single scoring system. We agree with Tokuhashi et al and Tomita et al that surgical treatment is beneficial if patient survival is beyond 6 months. Therefore, the distinction between these two patient groups is utmost important for us. This type of inaccuracy does not influence our treatment algorithm.

The survival of spinal metastasis patient is influenced by multiple variables including the patient and the tumour factors. Our study showed that general conditions, primary type of cancer, and visceral metastasis were independent survival factors in univariate and multivariate survival analysis. However, the influence

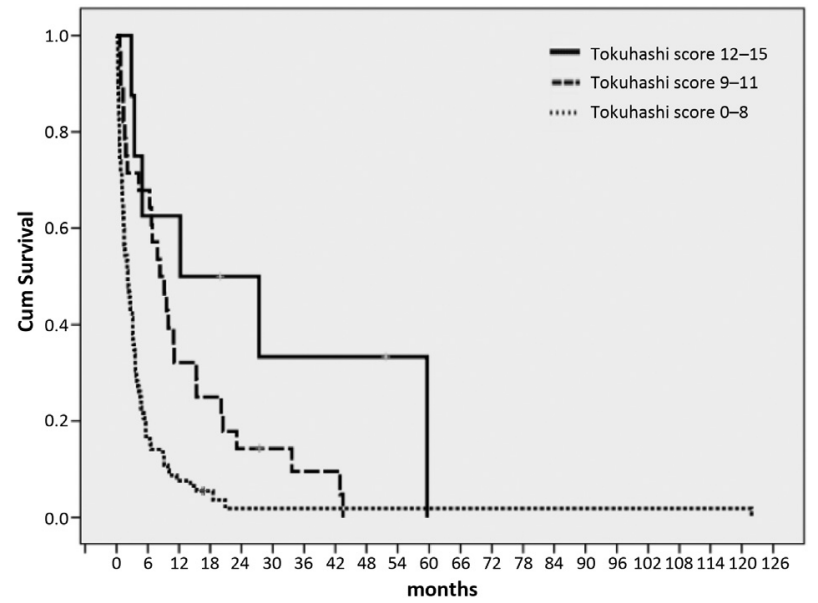

Figure 5. Survival curve for the three prognostic groups in all patients. Cum = cumulative
Table 4

Univariate analyses by Cox regression test

\begin{tabular}{lc}
\hline & $p$ \\
\hline Sex & $\mathbf{0 . 0 0 4}$ \\
Age & 0.052 \\
Level of vertebral metastasis & 0.577 \\
Revised Tokuhashi score & $<\mathbf{0 . 0 0 1}$ \\
General condition (KPS) & $\mathbf{0 . 0 0 1}^{*}$ \\
Number of vertebral metastases & $0.482^{*}$ \\
Number of extraspinal bone metastases & $0.264^{*}$ \\
Visceral metastasis & $\mathbf{0 . 0 0 1}$ \\
\hline
\end{tabular}

KPS = Karnofsky's performance status.

* Statistically significant.

of general condition as a prognostic factor for survival is controversial. $^{1-3,7-10,13,16}$ Karnofsky's performance status (KPS) ${ }^{20}$ is used for assessing the general condition in Tokuhashi scoring. Wibmer et al reported that poor KPS $(<40)$ had a better prognosis than moderate KPS (50-70), and the author explained that KPS might not reflect the general condition in spinal metastasis cases in which the patient had to be immobilised due to cord compression. ${ }^{7}$ Tomita et al did not accept the general condition as one of the prognostic factors, but instead suggested that the prognosis should be predicted by aggressiveness of cancer and visceral metastasis. ${ }^{3}$ Our result showed that general conditions in terms of KPS show a significant effect on patient survival. The hazard ratio (HR) was 6.89 for poor performance status (KPS 10-40) and 2.62 for the moderate performance status (KPS 50-70) compared with reference values. This result supports other literature reports that noted poor functional status associated with poorer survival. ${ }^{8,10,13}$

Another controversy was the prognostic value of neurological deficit. Harrington suggested that the rapid onset of muscular weakness had a considerable influence on the ultimate prognosis. ${ }^{14}$ Hosono et al reported that paresis was associated with poor survival. ${ }^{16}$ However, our study could not establish its significance in multivariate analysis. This result was compatible with other studies. $3,5,7-10,13$ In accordance with Tomita et al, patients with paralysis seem to die sooner because of progression of the cancer, and not because of the paralysis. ${ }^{3}$ We observed that the presence of visceral metastasis was associated with poorer survival with HR

Table 5

Multivariate analyses by Cox regression test

\begin{tabular}{lllll}
\hline Variables & Score & HR & $p$ & $95 \% \mathrm{CI}$ \\
\hline Sex & & 1.37 & 0.187 & $0.86-2.20$ \\
$\quad$ Neurological deficit (Frankel grade) & & & 0.623 & \\
$\quad$ Complete (A and B) & 0 & 0.67 & 0.3471 & $0.26-1.54$ \\
$\quad$ Incomplete (C and D) & 1 & 0.92 & 0.755 & $0.56-1.52$ \\
$\quad$ None (E) & 2 & 1 & & \\
General condition & & & $<\mathbf{0 . 0 0 1}^{*}$ & \\
$\quad$ Poor: KPS 10-40 & 0 & 6.89 & $<0.001$ & $3.07-15.46$ \\
$\quad$ Moderate: KPS 50-70 & 1 & 2.62 & 0.002 & $1.41-4.86$ \\
$\quad$ Good: KPS 80-100 & 2 & 1 & & \\
Visceral metastasis & & & $\mathbf{0 . 0 0 6}$ & \\
$\quad$ Unremovable & 0 & 1.73 & 0.009 & $1.15-2.62$ \\
$\quad$ Removable & 1 & 4.82 & 0.036 & $1.11-20.99$ \\
$\quad$ None & 2 & 1 & & \\
Primary cancer type & & & $\mathbf{0 . 0 0 1 5}$ & \\
$\quad$ Lung, bladder, stomach & 0 & 1.86 & 0.031 & $1.06-3.26$ \\
$\quad$ Liver, unidentified & 1 & 2.49 & 0.011 & $1.23-5.01$ \\
$\quad$ Others & 2 & 0.96 & 0.889 & $0.51-1.78$ \\
$\quad$ Kidney, uterus & 3 & 2.76 & 0.023 & $1.15-6.65$ \\
$\quad$ Rectum & 4 & 0.59 & 0.613 & $0.77-4.52$ \\
$\quad$ Breast, prostate, thyroid & 5 & 1 & &
\end{tabular}

$\mathrm{CI}=$ confidence interval; $\mathrm{HR}=$ hazard ratio; $\mathrm{KPS}=$ Karnofsky's performance status.

* Statistically significant. 
Table 6

Cox regression analyses between the three Tokuhashi prognostic groups

\begin{tabular}{llll}
\hline Tokuhashi prognostic groups & HR & $p$ & $95 \% \mathrm{CI}$ \\
\hline $\begin{array}{c}\text { Poor }(0-8 \text { points) versus good } \\
\quad(12-15 \text { points) } \mathrm{R}\end{array}$ & 4.226 & 0.001 & $1.81-9.88$ \\
$\begin{array}{c}\text { Moderate }(9-11 \text { points) versus } \\
\text { good }(12-15 \text { points) R }\end{array}$ & 1.856 & 0.174 & $0.76-4.53$ \\
$\begin{array}{c}\text { Moderate }(9-11 \text { points) versus } \\
\text { poor }(0-8 \text { points) } \mathrm{R}\end{array}$ & 0.439 & $<0.001$ & $0.28-0.69$ \\
\hline
\end{tabular}

$\mathrm{CI}=$ confidence interval; $\mathrm{HR}=$ hazard ratio; $\mathrm{R}=$ reference group.

ranging from 1.73 to 4.82 . This echoed the studies in the literature that reported that the extent of visceral metastasis had a significant impact on patient survival. ${ }^{1-3,7,9,10,13,16}$

The type of primary cancer was suggested to be the main prognostic factor affecting patient survival. ${ }^{1-5,7-10,13,16}$ Tokuhashi et al had revised the scoring system by diversifying the different primary cancers. $^{2}$ The impact of the types of cancer has been reflected by scoring of more points by types of tumours in the modified scoring system. Our analysis also supported this important prognostic factor in patient survival. Although the modified Tokuhashi scoring system had covered most of the cancers, some prevalent cancers in our locality such as nasopharyngeal carcinoma (NPC) have not been properly classified. NPC is endemic in South East Asia and Southern China. In Hong Kong, NPC is the seventh most frequent tumour. ${ }^{17}$ Although this aggressive tumour often presents with local infiltration and distant metastasis, aggressive treatment with radiotherapy and chemotherapy can achieve a reasonably high chance of cure and a relatively long-term survival even in a metastatic setting. Ngan et al reported a median survival of 15 months in metastatic or recurrent NPC patients treated with two-drug combinational chemotherapy. ${ }^{18}$ Leong et al demonstrated a median survival rate of 22 months in metastatic NPC patients treated with three-drug combinational chemotherapy. ${ }^{19}$ In our series, NPC constituted $7.8 \%$ of cases with a mean survival of 20.1 months \pm 37.6 and a median of 7 months (Table 7). When compared with other groups of cancer proposed by Tokuhashi, NPC showed significantly more favourable survival outcome. In view of the favourable response of NPC towards systemic chemotherapy and radiation therapy, we would recommend a higher scoring for NPC in the modified Tokuhashi scoring system.

The advancement of radiotherapy, chemotherapy, and immunotherapy has significantly improved the survival rate in different cancers. In accordance with Wibmer et al, we believe that the

Table 7

Survival related to different types of cancers

\begin{tabular}{lrlll}
\hline $\begin{array}{l}\text { Entity of primary } \\
\text { cancer }\end{array}$ & $N$ & Mean survival \pm SD (mo) & Range (mo) & $\begin{array}{l}\text { Median } \\
(\mathrm{mo})\end{array}$ \\
\hline Thyroid & 3 & $19.1 \pm 28.3$ & $2.1-51.7$ & 3.4 \\
Breast & 19 & $15.6 \pm 16.0$ & $0.8-59.6$ & 7.9 \\
Prostate & 12 & $7.3 \pm 8.8$ & $0.3-27.4$ & 3.2 \\
Rectum & 2 & $8.2 \pm 10.1$ & $1.0-15.3$ & 8.2 \\
Renal & 6 & $1.6 \pm 0.4$ & $1.3-2.2$ & 1.5 \\
Uterus & 2 & $5.8 \pm 4.7$ & $2.5-9.1$ & 5.8 \\
NPC & 10 & $20.1 \pm 37.6$ & $0.2-121.8$ & 7.0 \\
Colon & 8 & $5.4 \pm 7.0$ & $0.5-18.5$ & 1.7 \\
Others & 4 & $6.6 \pm 7.1$ & $0.3-16.8$ & 4.7 \\
Liver & 10 & $2.6 \pm 1.9$ & $0.3-20.9$ & 2.1 \\
Unidentified & 8 & $4.0 \pm 4.4$ & $0.4-11.1$ & 1.3 \\
Lung & 38 & $4.0 \pm 4.9$ & $0.3-20.9$ & 2.1 \\
Sarcoma & 1 & 5.6 & - & - \\
Stomach & 1 & 0.2 & - & - \\
Bladder & 3 & $1.2 \pm 1.1$ & $0.5-2.5$ & 0.6 \\
Oesophagus & 1 & 0.3 & - & - \\
\hline
\end{tabular}

$N=$ number of cases; NPC = nasopharyngeal carcinoma; SD = standard deviation aggressiveness of the tumour as well as its sensitivity towards systemic therapy should be considered in defining the prognosis of the patients in future.

However, the findings of the study might be biased by patientselection criteria and its retrospective nature. The patient group was heterogeneous and the number of cases was relatively small. This might affect the statistical power of the study. A multicentre study with a larger population is therefore suggested to better delineate the accuracy of the modified Tokuhashi scoring system in a Southern Chinese population. Besides, the outcome of the conservative treatment group may be biased due to the advancement in systemic treatment of cancer in recent years.

\section{Conclusion}

The modified Tokuhashi score was statistically correlated to the overall survival of patients with MSCC in a Southern Chinese population. General condition, primary type of cancer, and presence of visceral metastasis were independent predictors of overall survival. The poor prognostic group showed significantly worse survival than the two better prognostic groups. The modified Tokuhashi score was a significant tool to distinguish patients in the conservative group with predicted survival less than 6 months. We recommend a higher rating for NPC in the modified scoring system in view of its favourable prognosis. It is important that the decision of performing an operation should not be based on a single scoring system alone. Various factors, especially the response of the primary tumour to systemic therapy and radiotherapy, should be seriously considered. Therefore, a multidisciplinary approach with an oncologist should be advocated for every case of MSCC.

\section{Conflicts of interest}

The authors declare that they have no financial or non-financial conflicts of interest related to the subject matter or materials discussed in the manuscript. They have no relationship with any commercial company, including the implant company used in the study.

\section{References}

1. Tokuhashi Y, Matsuzaki H, Toriyama S, et al. Scoring system for the preoperative evaluation of metastatic spine tumor prognosis. Spine (Phila Pa 1976) 1990; 15:1110-3.

2. Tokuhashi Y, Matsuzaki H, Oda H, et al. A revised scoring system for preoperative evaluation of metastatic spine tumor prognosis. Spine (Phila Pa 1976) 2005:30:2186-91.

3. Tomita K, Kawahara N, Kobayashi T, et al. Surgical strategy for spinal metastases. Spine (Phila Pa 1976) 2001:26:298-306.

4. Ulmar B, Huch K, Naumann U, et al. Evaluation of the Tokuhashi prognosis score and its modifications in 217 patients with vertebral metastases. Eur J Surg Oncol 2007;33:914-9.

5. Enkaoua EA, Doursounian L, Chatellier G, et al. Vertebral metastases: a critical appreciation of the preoperative prognostic Tokuhashi score in a series of 71 cases. Spine (Phila Pa 1976) 1997;22:2293-8.

6. Ulmar B, Richter M, Cakir B, et al. The Tokuhashi score: significant predictive value for the life expectancy of patients with breast cancer with spinal metastases. Spine (Phila Pa 1976) 2005;30:2222-6.

7. Wibmer C, Leithner A, Hofmann G, et al. Survival analysis of 254 patients after manifestation of spinal metastases: evaluation of seven preoperative scoring systems. Spine (Phila Pa 1976) 2011;36:1977-86.

8. Pointillart V, Vital JM, Salmi R, et al. Survival prognostic factors and clinical outcomes in patients with spinal metastases. J Cancer Res Clin Oncol 2011;137: 849-56.

9. Leithner A, Radl R, Gruber G, et al. Predictive value of seven preoperative prognostic scoring systems for spinal metastases. Eur Spine J 2008;17: 1488-95.

10. Yamashita T, Siemionow KB, Mroz TE, et al. A prospective analysis of prognostic factors in patients with spinal metastases: use of the revised Tokuhashi score. Spine (Phila Pa 1976) 2011;36:910-7. 
11. Patchell RA, Tibbs PA, Regine WF, et al. Direct decompressive surgical resection in the treatment of spinal cord compression caused by metastatic cancer: a randomised trial. Lancet 2005;366:643-8.

12. Fujibayashi S, Neo M, Miyaki K, et al. The value of palliative surgery for metastatic spinal disease: satisfaction of patients and their families. Spine 2010;10:42-9.

13. van der Linden YM, Dijkstra SP, Vonk EJ, et al. Prediction of survival in patients with metastases in the spinal column: results based on a randomized trial of radiotherapy. Cancer 2005;103:320-8.

14. Harrington KD. Metastatic disease of the spine. J Bone Joint Surg Am 1986;68: 1110-5.

15. Putz C, Wiedenhöfer B, Gerner HJ, et al. Tokuhashi prognosis score: an important tool in prediction of the neurological outcome in metastatic spinal cord compression: a retrospective clinical study. Spine (Phila Pa 1976) 2008;33: 2669-74.
16. Hosono N, Ueda T, Tamura D, et al. Prognostic relevance of clinical symptoms in patients with spinal metastases. Clin Orthop Relat Res 2005;436:196-201.

17. Hong Kong Cancer Registry. 2009 Annual statistical report. Hong Kong: Hong Kong Hospital Authority; 2009.

18. Ngan RK, Yiu HH, Lau WH, et al. Combination gemcitabine and cisplatin chemotherapy for metastatic or recurrent nasopharyngeal carcinoma: report of a phase II study. Ann Oncol 2002;13:1252-8.

19. Leong SS, Wee J, Rajan S, et al. Triplet combination of gemcitabine, paclitaxel, and carboplatin followed by maintenance 5-fluorouracil and folinic acid in patients with metastatic nasopharyngeal carcinoma. Cancer 2008;113: $1332-7$.

20. Karnofsky DA. Clinical evaluation of anticancer drugs: cancer chemotherapy. GANN Monogr 1967;2:223-31. 